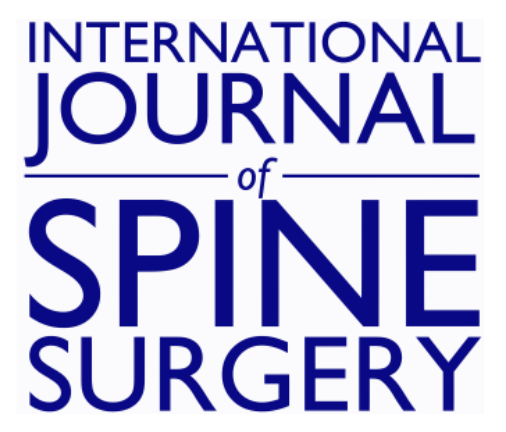

\title{
Who Should Decide How New Medical Technology Is Utilized? Completing the Algorithm With Existing Resources
}

Jack E. Zigler

Int J Spine Surg 2007, 1 (4) 160-162

doi: https://doi.org/10.1016/SASJ-2007-Comment

http://ijssurgery.com/content/1/4/160

This information is current as of April 26, 2023.

Email Alerts Receive free email-alerts when new articles cite this article. Sign up at:

http://ijssurgery.com/alerts

The International Journal of Spine Surgery

2397 Waterbury Circle, Suite 1,

Aurora, IL 60504, Phone: +1-630-375-1432

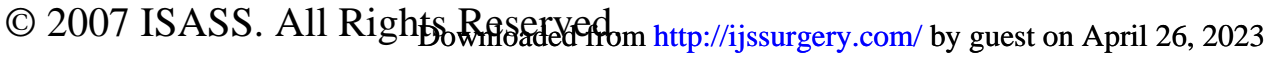




\title{
Who Should Decide How New Medical Technology Is Utilized? Completing the Algorithm With Existing Resources
}

\author{
Jack E. Zigler, MD, FACS, FAAOS
}

Imagine that you have disabling back pain. Not the transient acute back strain we have all experienced - that deep aching pain and sharp muscle spasm that prevents any activity. That pain typically goes away in a few days, leaving us as good as new and quickly forgetting that we ever had it. No, instead imagine a daily and constant aching pain that starts as soon as you wake up, lasts all day long, and gets even worse with any activity. Imagine that it intensifies after only a few minutes of sitting and commands you to change your position constantly, so that you fidget in your seat and must stand up every 10 or 15 minutes. Like a deep toothache, this pain makes it hard to concentrate on your work, makes it hard to pay attention to what your spouse or children are saying, and becomes a constant restrictive event in your life.

Imagine that you have been to your family physician and have tried medications with no improvement. You have been to a chiropractor, a physical therapist, a pain management physician, an acupuncturist, and a holistic healer and have combed the Internet for help. You have become dependent on ever-increasing doses of pain medication just to get dressed and get through the day. You have had $\mathrm{x}$-rays and an MRI scan. Your family physician tells you that your x-rays look normal but you have a degenerating disc and you need to be on medication, your chiropractor tells you that your sacroiliac joints are the problem and you need manipulation, and your pain management specialist tells you that your facet joints are the problem and you need injections. Understandably, you are confused.

Now your work is suffering because you can't concentrate on what you are doing. You cannot travel to business meetings. You start missing days of work because your back hurts so badly that you can't sit in the car for the 30-minute commute to work. Your boss has told you that your job is in jeopardy. Your wife has told you that she is fed up with staying home every weekend, and your kids have stopped asking you to play with them.

This has been going on for 6 months. You have done everything that anyone has suggested or prescribed. Your pain is getting worse every day, and you experience increasingly frequent episodes of even sharper and more disabling pain. These flareups now last longer and are precipitated by trivial activities, such as tying your shoes.

You are finally referred to a spine surgeon. She examines you, looks at your MRI, and tells you that you have an abnormal
L5-S1 disc and that your pain is probably coming from it. A discogram is suggested. You have no pain from discography at L3-4 or at L4-5, and you are told that both of these discs are normal. The discogram at L5-S1 is abnormal in appearance, and it instantly reproduces your pain pattern, making the pain flare up in the same areas that hurt every day. When local anesthetic is injected into the disc, the pain is completely relieved. It's the first time you have been without pain in over 6 months. After 3 hours the pain returns. The surgeon tells you that, based on strong scientific evidence, removal of the disk will significantly decrease your level of pain, reducing your reliance on pain medication and improving your function from day to day.

You have learned from your Internet research about surgical options. You understand that a fusion procedure will give you the improvement you have been hoping for, but you are more interested in considering an artificial disc replacement. Your surgeon tells you that you are a good candidate for arthroplasty because you fit the profile of the patients who were enrolled in prospective randomized multicenter multisurgeon trials in which arthroplasty patients did at least as well as fusion patients but had better motion than patients who had undergone a fusion procedure. You understand that patients enrolled in US studies were intensively reviewed for only 2 years after surgery and that no longer-term data are available other than a few isolated 5-year reports. Nevertheless, you are comfortable knowing that the technology has been around for 20 years in Europe, and you feel capable of making an informed decision for your own body. You want an artificial disc replacement.

Now you enter a new phase of your education. You naively assume that because you have been paying for health insurance, and because the FDA has reviewed intensive clinical data and approved several disc replacements for specific indications (which you are told you have met) you can opt for treatment with this technology. But your surgeon tells you that although your insurance carrier is in a position to approve a fusion procedure the company has decided to classify lumbar artificial disc replacement as experimental and will not authorize it as a treatment option for you. You can go through a tiered appeal process described in your insurance policy handbook, but your surgeon tells you, based on her experience with dozens of patients in the same situation, you will not get authorization for arthroplasty surgery. 
You were desperate before, but you are much more desperate now. Now you have a diagnosis. Now you have tried and failed every other therapeutic option. Now you are mentally prepared to undergo a major surgical procedure, but your insurance carrier prevents you from doing this. Secondopinion physicians (including some who are not specialists in the spine) hired by your carrier to "review your case" have denied your request and offer no better treatment options than more therapy, more medication, or recommendations to "live with the pain."

\section{Who Should Decide What Treatment Is Appropriate?}

It would be irresponsible and inappropriate to recommend a free-wheeling system in which patients themselves select the treatment they want. Non-medical folks are not in a position to evaluate the complexities of their own pathophysiology and the esoteric engineering research and development behind new technology. They are too easily swayed by well-meaning but uninformed recommendations from family members and coworkers, or even by slick but overly generalized advertisements in the media. Most importantly, patients cannot see their situation objectively because they are so intrinsically involved in their pain and disability that they cannot and should not be the ones to make this decision. Even surgeons who are patients will most appropriately leave treatment decisions to their own physicians, telling their doctors to do the procedure they themselves are most comfortable performing.

Should this decision be made by corporations? Insurance companies certainly value the good health of those they insure, but mainly because healthy clients utilize resources at a much lower cost to the insurance company than do sick clients. Less money paid out for health care means more money in the bank for the insurance company. This is a business model anyone can understand. Insurance companies promote wellness and preventive care not out of altruism but out of capitalism. An insurance company that approved and paid out unsupervised claims would likely be unprofitable and would not be able to sustain itself in the marketplace. But is this business the appropriate entity to decide whether new technology is appropriate for patient care? The company will not foot the bill until the bottom line is assured, and the timeline for this assurance may lag way behind the current needs of our patients.

Are individual physicians the best judges of new technology use? It is not likely that every physician can be up to speed on all the basic science and clinical research behind every new device and implant. Like patients, individual physicians are humans who are swayed by individual testimonials, glitzy advertising, or even word of mouth among their colleagues. If the world of innovation ran like this, as it did a century ago in the United States, surgeons would still be inventing devices in their garages and implanting them in their patients without supervision. We are clearly beyond this stage.
Regulation is a mixed blessing. It tends to slow down the introduction of new technology, which has become prohibitively more and more expensive. New technology testing is now so expensive that the government cannot fund it, and the modern paradigm calls for industry to finance its own testing, with governmental oversight. This situation has decreased the number of new IDE studies over the past 10 years but has also led to a better quality of science in clinical testing.

Should it then be the FDA who decides? The latest IDE trials have used the "cleanest" clinical testing models that are ethical and reasonable to perform: multicenter prospective randomized controlled trials. Multicenter participation removes the bias of individual investigators, particularly if they happen to be the inventors or developers of the device. Prospective randomization removes selection bias, verified by comparison of the investigative and control group demographics, to assure reviewers that the groups are comparable, so the only variable that should influence outcome is the investigative device. We are using better, more uniform, validated instruments for evaluating outcomes. Monitoring by the FDA helps assure us that clinical testing is done properly, and that data collection is performed objectively and competently, with patient safety foremost.

Data from these trials are presented at international meetings where informed audiences can challenge the study design and interim results and can offer different interpretations of the same data. Investigators report the results of these studies in peer-reviewed journals where scholarly editorial boards force the authors to hone their writing skills, data presentation, and conclusions. Debate often continues in letters to the editor or published counterpoint. Multispecialty societies offer symposia on these topics to invite disparate views and additional public debate.

Our professional societies should be the final filter through which the role of new technology is determined. After scrupulous governmental oversight has cleared the device as safe and effective when it is used in the manner prescribed by the criteria of the study, careful review of scientifically generated results, debated in open society forums by professionals with expertise in the treatment area, should lead to consensus policy statements guiding the use of the new technology. These consensus policies should be respected by governmental agencies, insurance companies, individual physicians, and finally, by patients themselves.

Individual patients who are in pain and in difficult social straits should not choose their own device or surgical procedure. An individual surgeon swayed by an attractive brochure and a persuasive salesperson should not choose the device. An insurance company that is concerned with spending less than it takes in should not determine the appropriate use of a device for a patient's care. The system currently in place, with governmental regulation of an unbiased rigorous scientific clinical trial to determine safety and efficacy for specific 
indications, followed by scientific debate in public forums and in the scientific literature, should serve to "clear" new technology for consideration.

This part of the algorithm is already in place. Scientific societies such as SAS, NASS, CSRS, and SRS now need to pick up the torch and complete the process. These groups should be given the task of producing a consensus statement to guide patients, and, by governmental mandate, payors. Postmarket surveillance, by society subcommittees under FDA review, should allow for monitoring of these guidelines, with modifications made as necessary.

Individual patients should choose their care after reviewing available options with their physicians, who should never forget that one of their main roles is as teachers, educating their patients about their disease process and the various treatment alternatives available. The patient-physician couple should have available to them any and all treatment options that have passed the clearinghouse of governmental oversight, peerreviewed analysis, and finally, scientific society imprint. The ultimate decision should be with the informed patient and his physician. The medical office consultation room is where this decision needs to occur-never in the boardroom.

The framework of the system is in place, but the final society recommendation process has not yet been formalized. This is the task we as treating physicians need to address, designing the final segments to close the loop. Only then can we demonstrate that the best interests of the patient have been and will continue to be met.

SAS Journal. Autumn 2007; 1:160-162. DOI: SASJ-2007-Comment

Jack E. Zigler, MD, FACS, FAAOS, Texas Back Institute, Plano, Texas

Address correspondence to Jack E. Zigler, MD, Texas Back Institute, 6020

West Parker Road \#200, Plano, Texas 75093 